\title{
Bio-optical properties of the marine diazotrophic cyanobacteria Trichodesmium spp. II. A reflectance model for remote sensing
}

\author{
Ajit Subramaniam ${ }^{1}$ and Edward J. Carpenter \\ Marine Sciences Research Center, SUNY at Stony Brook, Stony Brook, New York 11794-5000
}

\section{Paul G. Falkowski}

Environmental Biophysics and Molecular Biology Program, Institute of Marine and Coastal Sciences, Rutgers University, 71 Dudley Road, New Brunswick, New Jersey 08901-8521

\begin{abstract}
The spatial and temporal distribution of Trichodesmium in the world's oceans is highly variable and can potentially be assessed using satellite imagery. Distinguishing these organisms from other phytoplankton in the upper ocean using remotely sensed information, however, requires an optical model that uniquely characterizes Trichodesmium. Here, we parameterize a standard remote-sensing reflectance model using measured values of Trichodesmium's inherent optical properties, namely the spectral dependence of the chlorophyll-specific optical absorption crosssections and the spectral dependence of the chlorophyll-specific backscatter cross-sections. Values for the chlorophyll-specific absorption cross-sections are described in the previous paper. We calculated the spectral chlorophyllspecific backscattering cross-section $\left(b_{b}^{*}\right)$ from measurements of the chlorophyll-specific volume-scattering function and the spectral backscatter coefficients. $b_{b}^{*}$ was $0.0027 \mathrm{~m}^{2}(\mathrm{mg} \text { chlorophyll } a[\mathrm{Chl} a])^{-1}$ at $436 \mathrm{~nm}$ and $0.002 \mathrm{~m}^{2}$ $(\mathrm{mg} \mathrm{Chl} a)^{-1}$ at $546 \mathrm{~nm}$; these cross-sections are approximately one order of magnitude higher than those for "typical" phytoplankton. The optical model revealed that the combination of high backscatter, absorption, and fluorescence could be used to distinguish moderate to high concentrations $\left(>1 \mathrm{mg} \mathrm{Chl} \mathrm{m}^{-3}\right)$ of Trichodesmium from other phytoplankton. The model also predicted that surface scum blooms of Trichodesmium would have high reflectance in the near infrared. The high reflectance feature of surface Trichodesmium blooms was used in conjunction with sea truth and data from the advanced very high resolution radiometer (AVHRR) to map a 300,000$\mathrm{km}^{2}$ Trichodesmium bloom off the Somali Coast in May 1995. The nitrogen fixed by this bloom was estimated to be $9.4 \times 10^{8} \mathrm{gN} \mathrm{d}^{-1}$. These results demonstrate the potential of using remote-sensing techniques in the estimation of nitrogen fixation and the contribution of nitrogen fixation to global biogeochemical processes.
\end{abstract}

One of the most attractive aspects of remote-sensing information is the potential to derive fluxes from estimates of standing stocks. In biological oceanography, changes in optical properties have been used to infer upper ocean chlorophyll concentrations, which can, in turn, be related to primary productivity (Longhurst et al. 1995; Antoine et al.

\footnotetext{
${ }^{1}$ Present address: Chesapeake Biological Laboratory, P.O. Box 38, Solomons, Maryland 20688.

\section{Acknowledgments}

This work was funded by the NASA Global Change Graduate Fellowship to A.S., and the support received from NASA is gratefully acknowledged. A.S. would like to thank Gary Borstad for introducing him to remote sensing. A.S. is especially grateful to Shubha Sathyendranath for her kindness, patience, and useful discussions. We thank D. G. Capone and J. Zehr for ship time and acknowledge the help rendered by the masters and crew of the RVs Columbus Iselin and Seward Johnson, especially the electronic technicians and engineers on board. We thank Howard Gordon and Ken Voss for making the Bryce Phoenix instrument available and facilitating the chlorophyll-specific backscatter measurements, and we especially thank Kay Kilpatrick for providing the software and helping with the calculation of $b_{b}^{*}$. Bob Evans and Joanie Splain provided the AVHRR data. We thank the anonymous reviewers for their comments.

P.G.F. was supported by the U.S. Department of Energy under contract DE-AC02-76CH00016 and NASA under grant UPN16135-05-08. E.J.C. was supported by NSF grants OCE9317738 and DEB9633744. This is MSRC contribution number 1142.
}

1996; Behrenfeld and Falkowski 1997). It has heretofore been very difficult, however, to quantify the temporal and spatial extent of new production in the oceans, let alone the contribution of $\mathrm{N}_{2}$ fixation to that flux. The latter plays a critical role in regulating carbon fixation (Capone et al. 1997; Falkowski 1997), and uncertainty in $\mathrm{N}_{2}$ fixation has prevented a quantitative analysis of new production and the factors that lead to its change. The nonheterocystous, colonial cyanobacterium, Trichodesmium spp., is responsible for most of the $\mathrm{N}_{2}$ fixation in the open oceans (Capone et al. 1997). Hence, a remote-sensing algorithm capable of distinguishing these organisms from all other phytoplankton would be of enormous value in constraining estimates of $\mathrm{N}_{2}$ fixation in the world's oceans.

Together, the optical properties and physiological behavior of Trichodesmium potentially provide a basis for developing algorithms capable of uniquely identifying and quantifying their distributions based on remotely sensed information (Subramaniam and Carpenter 1994). For example, Trichodesmium forms extensive surface blooms that discolor vast regions of tropical and subtropical seas. Gas vacuoles within the cells produce large changes in refractive index relative to the surrounding cytoplasm and water, increasing Trichodesmium's contribution to the backscattered light (Borstad et al. 1992). Additionally, the unique absorption characteristics (Subramaniam et al. 1999), in conjunction with high reflectance, potentially permit the application of red/near-in- 
frared radiance reflectance-based indices for the retrievals of the spatial and temporal distributions of these cyanobacteria.

Here, we analyze the backscatter properties of Trichodesmium and, in conjunction with absorption properties (Subramaniam et al. 1999), parameterize a remote-sensing reflectance model that can be used to derive algorithms from satellite observations of ocean color in the visible and near infrared. From numerical sensitivity analysis of simulated data, we demonstrate the applicability of the model in uniquely identifying Trichodesmium under a variety of oceanographic regimes, and we apply the model to map blooms of the organism in the Arabian Sea.

\section{Development of the remote-sensing reflectance model}

After correcting for atmospheric scattering and absorption, satellite ocean color sensors measure water-leaving radiances, which are apparent optical properties. Optical models are used to relate water-leaving radiance (or remote-sensing reflectance) to inherent optical properties of seawater and its constituents through empirical radiative transfer equations. Gordon et al. (1975) derived an expression from Monte Carlo simulations for approximate numeric solutions to the radiative transfer equations, that related the apparent optical property, $R$, to the inherent optical properties $a$ and $b_{b}$ :

$$
R(\tau)=\sum_{n=0}^{n=3} r_{n}(\tau) x^{n}
$$

where $R$ is the irradiance reflectance $\left(R=E_{u} / E_{d}\right.$, where $E_{u}$ and $E_{d}$ are the upwelling and downwelling irradiances, respectively), $x=\left(b_{b} / a+b_{b}\right), a$ is absorbance $\left(\mathrm{m}^{-1}\right), b_{b}$ is the backscattering coefficient $\left(\mathrm{m}^{-1}\right), \tau$ is the optical depth, and $r_{n}$ is the coefficient of expansion. $r_{0}\left(\tau_{0}\right)$ ranges from 0.0001 to 0.0003 , and $r_{1}\left(\tau_{0}\right)$ ranges from 0.3244 to 0.3687 for clear sky and overcast cases. Considering only the first term of the expansion and neglecting $r_{0}(\tau)$, one obtains at the surface $(\tau=0)$

$$
R=r_{1}\left(\frac{b_{b}}{a+b_{b}}\right) .
$$

An average value $r_{1}=0.33$ is valid for a wide range of solar zenith angles and sky conditions and for values of $b_{b} /$ $a$ up to 0.25 (Kirk 1984; Morel and Gentili 1993). Hence, the following relationship is often used to model irradiance reflectance:

$$
R(\lambda)=0.33 \frac{b_{b}(\lambda)}{a(\lambda)} .
$$

Immediately above the surface of the ocean, water-leaving radiance is described by the remote-sensing reflectance, $R_{r s}$,

$$
R_{r s}(\lambda)=\frac{L_{w}(\lambda)}{E_{T}}
$$

where $L_{w}$ is the water-leaving radiance, and $E_{T}$ is the total downwelling irradiance. $L_{w}$ is related to the subsurface upwelling radiance $L_{u}$ by

$$
L_{w}(\lambda)=\frac{t}{n^{2}} L_{u}(\lambda)
$$

where $t$ is the transmission across the water-air interface (taken to be ca. 0.97), for a nadir viewing instrument and calm surface, and $n=1.341$, an average refractive index of seawater with respect to air (Austin 1974 as quoted in Carder and Steward 1985). $L_{u}$ is related to the upwelling irradiance $E_{u}$ by the $Q$ factor; $L_{u}=E_{u} / Q . Q$ is here taken to be 5.08 (Carder and Steward 1985).

From the above relations and equations, we derive

$$
R_{r s}=0.1079 \frac{b_{b}}{a} .
$$

The terms $b_{b}$ and $a$ in Eq. 6 are inherent optical properties and can be partitioned into their constituents (Kirk 1994). For heuristic purposes, we consider the primary backscattering constituents to be seawater $\left(b_{b w}\right)$, phytoplankton $\left(b_{b p}-\right.$ due to Trichodesmium or other phytoplankton or Synechococcus), and detritus $\left(b_{b d}\right)$. As the scattering by seawater is isotropic, $b_{b w}=1 / 2 b_{w}$. Values of $b_{w}$ for seawater were taken from Smith and Baker (1981). The term $b_{b p}$ for Trichodesmium was measured as described below. $b_{b p}$ for "typical" phytoplankton was modeled following Morel (1988), using a backscatter efficiency of $0.2 \%$ for phytoplankton and the relationship $b=0.30 C^{0.62}$ between total scatter $b$ and chlorophyll concentration $C$ (Gordon and Morel 1983). $b_{b d}$ was modeled following Morel (1988), assuming (1) that the concentration of detritus varies inversely with chlorophyll concentration, and (2) that the backscatter due to detritus varies inversely with wavelength and is approximately $2 \%$ for chlorophyll concentration of $0.01 \mathrm{mg} \mathrm{m}^{-3}$. Thus, the backscatter due to detritus is expressed as

$$
b_{b d}=0.30 C^{0.62}\left[2 \cdot 10^{-2}\left(\frac{1}{2}-\frac{1}{4} \log C\right)\left(\frac{550}{\lambda}\right)\right] .
$$

The primary absorbing constituents are those of seawater $a_{w}$, phytoplankton $a_{p}$ (Trichodesmium or other phytoplankton or Synechococcus), and colored dissolved organic matter (CDOM) $a_{\text {cdom }}$. The absorption of seawater, $a_{w}$, was taken from Morel and Prieur (1977). $a_{p}$, the absorption due to Trichodesmium and Synechococcus, was measured as described (Subramaniam et al. 1999). The absorption cross-section of "other phytoplankton" was taken as the arithmetic mean of nine species representing different taxa (Sathyendranath pers. comm., based on the data in Sathyendranath et al. 1987). Carder et al. $(1989,1991)$ derived a relationship for absorption due to colored dissolved organic matter $\left(a_{\text {cdom }}\right)$; thus,

$$
\begin{gathered}
a_{\text {cdom }}=C_{d p}\left[0.1304\left(1-f^{\prime}\right) e^{0.011(450-\lambda)}\right. \\
\left.+0.0073 f^{\prime} e^{0.019(450-\lambda)}\right]
\end{gathered}
$$

where $C_{d p}$ is the concentration of CDOM, and $f^{\prime}$ is the fulvic acid fraction. The paired values of $C_{d p}=0.20, f^{\prime}=0.92$ and $C_{d p}=3.3, f^{\prime}=0.88$ were chosen corresponding to values in the middle of the Pacific Ocean and off the coast of California, respectively (see table 2 in Carder et al. 1991), representing high gilvin and low gilvin conditions. The terms $b_{b p}$ and $a_{p}$ can be expressed as the product of the chlorophyllspecific cross-section and the chlorophyll concentration (i.e., $b_{p}=b_{b p}^{*}[C]$ and $a_{p}=a_{p}^{*}[C]$, where $[C]$ is the chlorophyll 
concentration). From the above equations, Eq. 7 can be rewritten as

$$
R_{r s}=\frac{0.1079\left(b_{b w}+b_{b p}^{*}[C]+b_{b d}\right)}{a_{w}+a_{p}^{*}[C]+a_{\text {cdom }}} .
$$

Equation 9 forms the basis of an optical model that can be used to derive remote-sensing algorithms for the specific retrieval of Trichodesmium from remotely sensing waterleaving radiances. The organism-specific variables in the equation are $a_{p}^{*}$ and $b_{b p}^{*}$. These were empirically determined for Trichodesmium.

\section{Materials and methods}

Backscatter measurements of Trichodesmium-Chlorophyll-specific backscatter coefficients were estimated at two wavelengths. A Bryce Phoenix light-scattering photometer (model 2000) was used to measure the volume-scattering function $(\beta[\theta])$ of Trichodesmium samples at 436 and 546 $\mathrm{nm}$ for $0,45,90$, and $135^{\circ}$. A dissymetry cell (semioctagonal cross-section) containing about $50 \mathrm{ml}$ of Trichodesmium culture was illuminated by a collimated beam of a mercury vapor lamp. Measurements for the two wavelengths and four angles were done in random. The samples were stirred between measurements. $\beta(\theta)$ values for the same sample taken many minutes apart were not significantly different, indicating that the sample was homogeneous within the beam path for the duration of the measurements-i.e., the colonies did not float out of the beam path. These data were used to calculate the light-scattering phase function from 90 to $180 \mathrm{E}$ (see Gordon 1976), which was then integrated to obtain the backscattering coefficient $b_{b}\left(\mathrm{~m}^{-1}\right)$. The contents of the cuvette were filtered on $\mathrm{GF} / \mathrm{F}$ filters and frozen for subsequent chlorophyll analysis by standard fluorometric methods (Strickland and Parsons 1972). The chlorophyll-specific backscattering cross-section was obtained by dividing the total backscattering coefficient for each measurement by the chlorophyll concentration ( $\mathrm{mg} \mathrm{Chl} a \mathrm{~m}^{-3}$ ). The backscattering spectrum of Trichodesmium was measured using a technique similar to that described by Ahn et al. (1992) (Fig. 1). A Xenon arc lamp with a stabilized power supply was used as the light source. A 3.2-mm fused silica fiber-optic bundle with a collimating lens was used to deliver a beam of light into a Labsphere 6-in. integrating sphere. This beam was targeted to strike the sample cuvette with a normal angle of incidence. The integrating sphere had three ports. The input port for the collimated beam of light and the sample port that held the sample cuvette were $180^{\circ}$ apart. The third port, an exit port, was placed between the entrance and sample ports at $90^{\circ}$ to each (Fig. 1). Thus, the light sampled at the exit port was proportional to the light present in the integrating sphere. The sample cuvette (Fig. 1) was shaped like a horn, and its walls were made of blackened Pyrex glass. Its front window was made of quartz, the refractive index of which was very close to that of water. This was to minimize loss of backscattered light due to reflection off the window. The cuvette had two ports, one through which to pour the sample and the other for bubbles to escape. Because they contain gas vesicles, Trichodesmium colonies typically
(A)

Light Guides

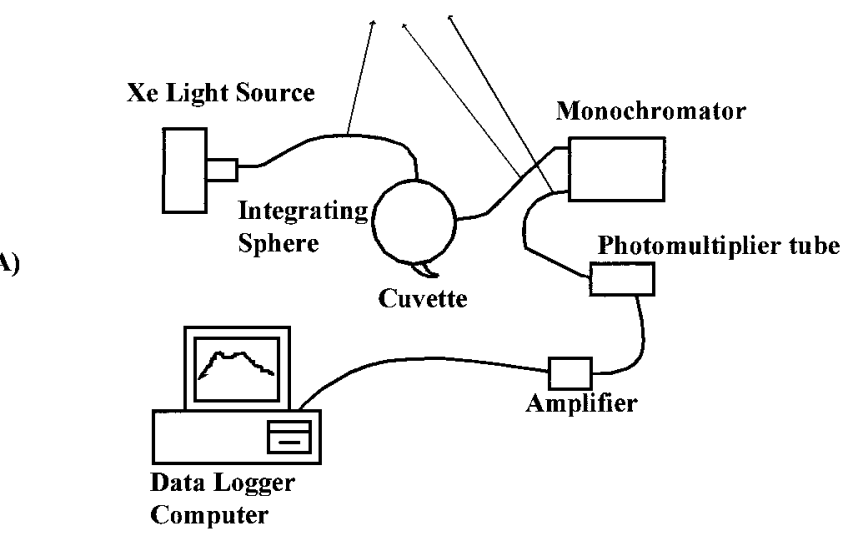

(B)

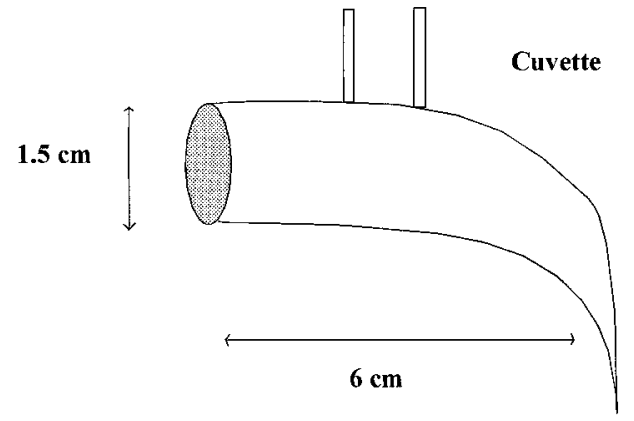

Fig. 1. (A) Arrangement of instruments used to measure the backscattering spectrum. The xenon lamp was used to illuminate the sample inside the cuvette with white light. The spectrum of the light field inside the integrating sphere that included the light backscattered by Trichodesmium inside the cuvette was sampled by a monochromator/pmt arrangement. (B) An enlarged view of the cuvette. The horn-shaped cuvette acted as a light trap and had a quartz window and black walls to minimize internal reflection. The two ports were used to fill the cuvette with samples without introducing bubbles. The cuvette was attached to the integrating sphere in such a fashion as to place the Trichodesmium colonies against the quartz window.

float to the surface. The integrating sphere was arranged such that the face of the cuvette looked upward, causing the colonies to float to the window of the cuvette.

The spectrum of the light exiting the integrating sphere was measured with a monochromator and a side-on photomultiplier tube. A fiber-optic bundle delivered polychromatic light to the monochromator that was scanned at $0.5 \mathrm{~nm} \mathrm{~s}^{-1}$ from 350 to $750 \mathrm{~nm}$. The entrance and exit slit widths were optimized to provide a 21-nm bandwidth. The current output of the photomultiplier tube was amplified using an operational amplifier. Data were acquired at $0.5 \mathrm{~Hz}$ using an analog/digital converter attached to a laptop computer. The scans were aggregated to 2-nm intervals and then smoothed using a five-point moving average filter.

\section{Results}

Basic optical measurements and parameterization of the remote-sensing reflectance model-Use of Eq. 9 requires the calculation of absorption and backscatter coefficients for the 


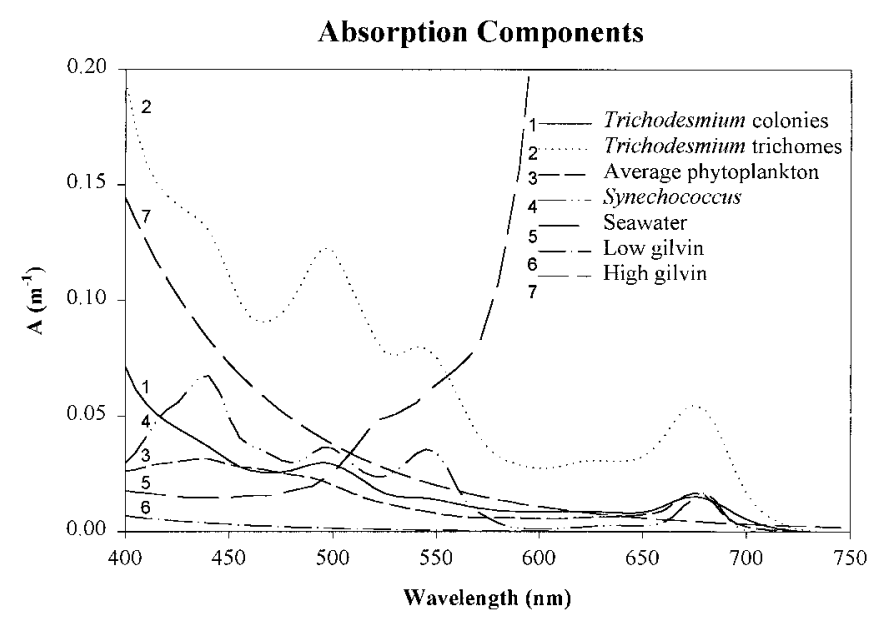

Backscattering Components

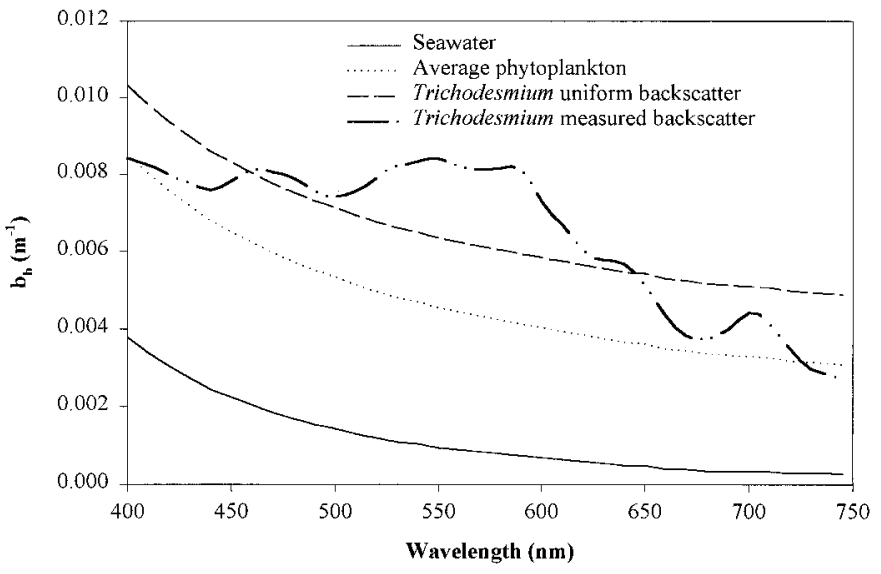

Fig. 2. (A) Absorption components contributing to the reflectance signal. Absorptions due to Trichodesmium colonies, trichomes, and Synechococcus were measured in this study. Absorption due to seawater is from Morel and Prieur (1977). Absorption due to "average phytoplankton" was calculated from eight species reported by Sathyendranath et al. (1987). Absorption due to gilvin was modeled after Carder et al. (1991). (B) Backscattering components contributing to the reflectance signal. The average phytoplankton and Trichodesmium backscatter include the detritus and water terms as defined by Morel (1988). "Trichodesmium measured backscatter" refers to the empirically measured spectral backscatter scaled by the empirically derived chlorophyll-specific backscatter. The "Trichodesmium uniform backscatter" used the empirically derived chlorophyll backscatter term to scale the Morel (1988) model. "Average phytoplankton" shows the backscattering of phytoplankton as modeled by Morel (1988).

ensemble of constituents that make the reflectance signal. In the case of the calculation of absorption coefficients, the model components include water, gilvin (i.e., CDOM), Trichodesmium, Synechococcus, and "other phytoplankton." Typical spectra for each of the individual components are shown in Fig. 2A. The proportion of each component to overall remote-sensing reflectance can be altered within the context of Eq. 9 to assess the sensitivity of the reflectance to that component. It should be noted that the chlorophyllspecific optical absorption cross-section measured for trichomes (i.e., a single filament) of Trichodesmium is higher than that obtained for intact colonies as a consequence of a reduction in self-absorption resulting from secondary packaging effects in the latter (Subramaniam et al. 1999).

The backscatter coefficient for Trichodesmium is wavelength dependent. The spectral variability for backscattered light (Fig. 2B) results both from reabsorption and from fluorescence; however, the latter plays a major role in determining the observed backscattering cross-section. "Backscatter" peaks centered between 550 and 570 and at $640 \mathrm{~nm}$ are a consequence of phycoerythrin and allophycocyanin fluorescence, respectively, rather than true elastic backscatter. Typically, chlorophyll fluorescence emission overwhelms the red absorption band, such that the backscatter spectrum reveals a peak in this region (Ahn et al. 1992). However, since Trichodesmium has a high photosystem I to photosystem II ratio (PSI : PSII) (Subramaniam et al. 1999), there is a net reduction in the backscatter spectrum between 670 and $690 \mathrm{~nm}$. This spectral characteristic permits the potential application of red/near-infrared reflectance ratios to qualitatively map blooms of the Trichodesmium at the air-sea interface from remotely sensed data (see below). The absolute value for the chlorophyll-specific backscattering cross-section was calculated at 436 and $546 \mathrm{~nm}$. The measured values for intact colonies of Trichodesmium $\left(b_{b}^{*} \mathrm{~m}^{2}[\mathrm{mg} \mathrm{Chl}]^{-1}\right)$ were 0.0027 $\pm 0.0005 \mathrm{~m}^{2}(\mathrm{mg} \mathrm{Chl})^{-1}$ at $436 \mathrm{~nm}$ and $0.0020 \pm 0.0003$ $\mathrm{m}^{2}(\mathrm{mg} \mathrm{Chl})^{-1}$ at $546 \mathrm{~nm}$. These values are, on average, one order of magnitude larger than those for pelagic unicellular phytoplankton, including Synechococcus, that do not contain gas vacuoles (Ahn et al. 1992).

To estimate the contribution of fluorescence to the total observed backscatter cross-section, we assumed that the "true" elastic backscatter spectrum of pure Trichodesmium was "white," i.e., had no wavelength dependence. When the influence of "detritus" and water are included, the backscatter spectrum follows an inverse function of wavelength (Morel 1988). Using an average of the measured backscatter coefficients at $436 \mathrm{~nm}$ (where fluorescence is minimal, but absorption is high) and $546 \mathrm{~nm}$ (where absorption is low, but fluorescence is high), we calculated the elastic backscatter coefficients as a function of wavelength in seawater in the presence of detritus (Fig. 2B). These results were subsequently applied in Eq. 9 to assess the sensitivity of the remote-sensing reflectance to solar-induced fluorescence emanating from Trichodesmium. Satellite measurements of water-leaving radiance will contain the contribution of fluorescence. We have treated the fluorescence signals as a component of backscatter in Eq. 9.

Remote-sensing reflectance spectra of phytoplankton blooms typically contain a "green peak," centered around $575 \mathrm{~nm}$. The peak is a consequence of an absorption minimum in that portion of the spectrum in most phytoplankton taxa, coupled with a sharp increase in the water absorption spectrum. As a consequence of both the intrinsically high elastic backscatter and phycoerythrin fluorescence, however, the remote-sensing reflectance around $575 \mathrm{~nm}$ for blooms of Trichodesmium is extremely high. The reflectance is approximately fivefold higher than that for Synechococcus or "typical" phytoplankton at high densities of chlorophyll biomass (10 mg Chl m${ }^{-3}$, Fig. 5A). To study the effect of phycoerythrin fluorescence on the reflectance spectra, we parame- 


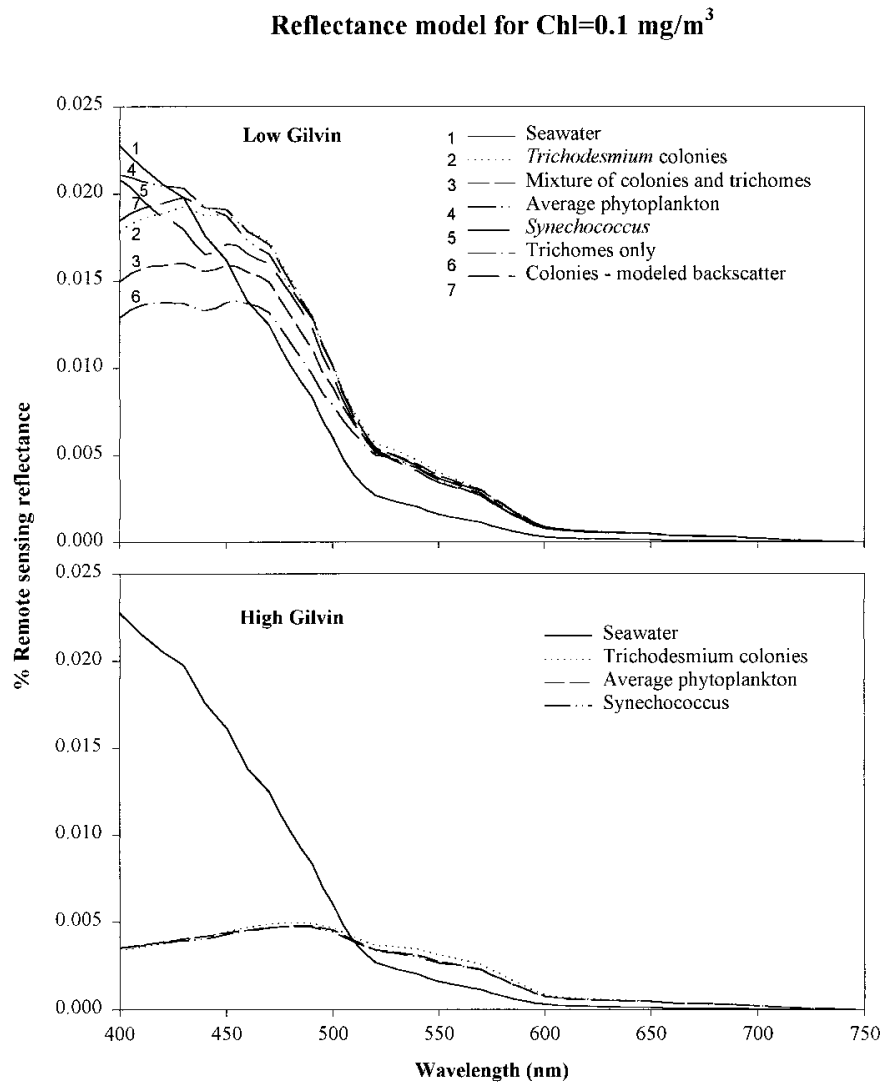

Fig. 3. Reflectance model for chlorophyll $=0.1 \mathrm{mg} \mathrm{m}^{-3}$. (A) Under low gilvin conditions, backscatter due to water dominates the reflectance signal. (B) Under high gilvin conditions, absorption due to gilvin dominates the reflectance signal.

terized Eq. 9 using a theoretical backscatter spectrum for "typical" phytoplankton (Morel 1988). The computed reflectance spectra were compared with those obtained using the spectrally measured backscatter coefficients (Figs. 3-5). However, it must be emphasized that while we have demonstrated that the "green peak" is enhanced by phycoerythrin fluorescence, we have not tried to quantify this enhancement.

Model sensitivity-Spectral remote-sensing reflectance values were calculated for three cases, representing a wide range of oceanographic optical regimes. These three cases correspond to average values of upper ocean chlorophyll concentrations of $0.1,1.0$, and $10.0 \mathrm{mg} \mathrm{m}^{-3}$, in the presence of two concentrations of gilvin. Thus, for example, for each case, the remote-sensing reflectance was calculated for a hypothetical condition of pure Trichodesmium colonies, trichomes, a mixture of the two, "other phytoplankton," and pure Synechococcus. A special case of surface blooms of Trichodesmium was also considered, in which the optical properties of seawater were eliminated.

At chlorophyll concentrations of $0.1 \mathrm{mg} \mathrm{m}^{-3}$, the contribution of backscattering from seawater dominated the remote-sensing reflectance. Phycoerythrin fluorescence from Trichodesmium was not detectable. The only clear difference

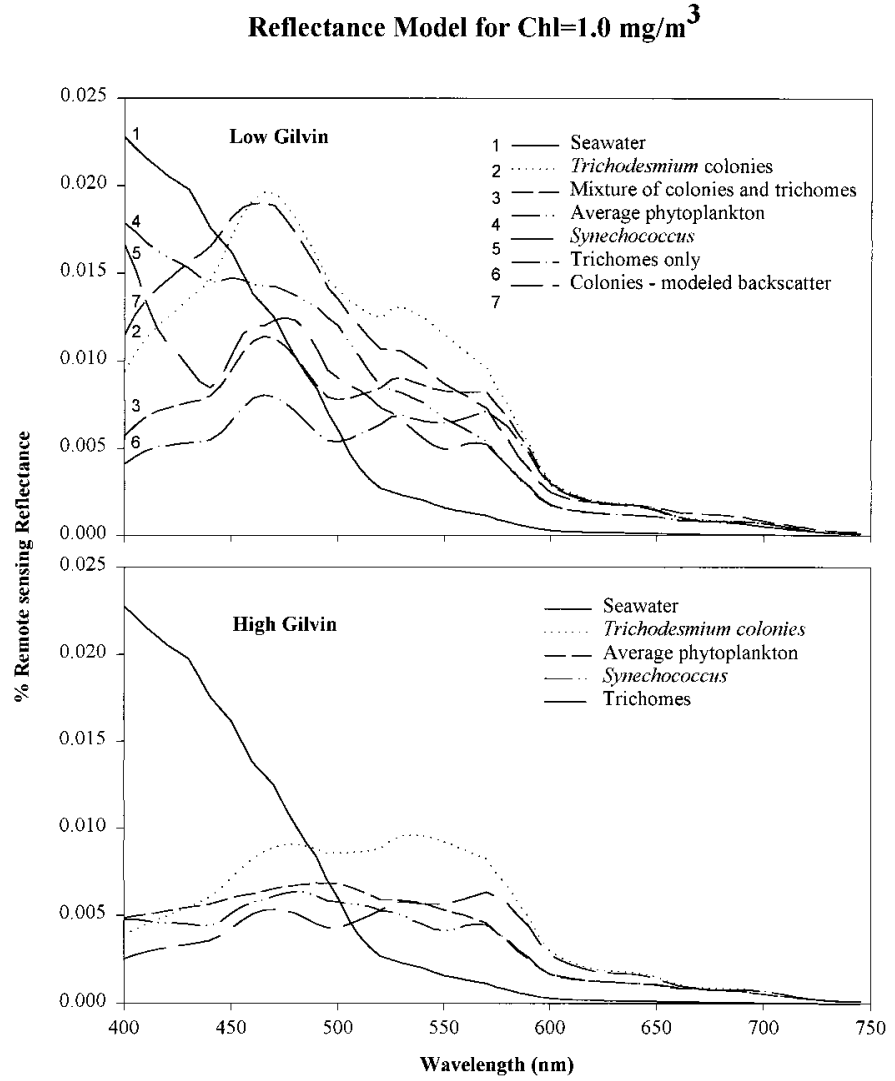

Fig. 4. Reflectance model for chlorophyll $=1.0 \mathrm{mg} \mathrm{m}^{-3}$. (A) Under low gilvin conditions, Trichodesmium colonies are distinctly different from the others. (B) Under high gilvin conditions, the difference is reduced by the absorption due to gilvin.

between remote-sensing reflectance spectra for the various conditions considered was due to the differential absorption characteristics of trichomes and colonies. Reflectance due to trichomes was noticeably lower in the blue end of the spectrum $\left(R_{440}\right.$ [reflectance at $\left.440 \mathrm{~nm}\right]=1.4 \%$ compared to $R_{440}$ $=1.8 \%$ for colonies-Fig. $3 \mathrm{~A}$ ). Changes in gilvin concentration (i.e., absorption effect) made a large difference to the retrieved reflectance spectra $\left(R_{440}=0.2 \%\right.$ for Trichodesmium colonies in high gilvin, compared to $R_{440}=1.8 \%$ in low gilvin-Fig. 3B). Under high gilvin conditions, all reflectance spectra (whether due to colonies, trichomes, Synechococcus, or "other" phytoplankton) had similar magnitudes and spectral shapes.

At moderate chlorophyll concentrations $(\mathrm{Chl}=1.0 \mathrm{mg}$ $\mathrm{m}^{-3}$ ), a marked difference emerged between Trichodesmium colonies and other phytoplankton. The difference was greatest around 470 and $550 \mathrm{~nm}$ (Fig. 4A). Although there was some contribution by phycoerythrin fluorescence from Trichodesmium in this region of the spectrum, the bulk of the difference was due to elastic scattering. At this chlorophyll concentration, the remote-sensing reflectance was moderately sensitive to absorption characteristics within the system. For example, the difference between trichomes and colonies of Trichodesmium is readily distinguishable in the reflectance spectra, as is the difference between either trichomes or colonies of Trichodesmium and Synechococcus. At high 
Reflectance model for $\mathrm{Chl}=10 \mathrm{mg} / \mathrm{m}^{3}$

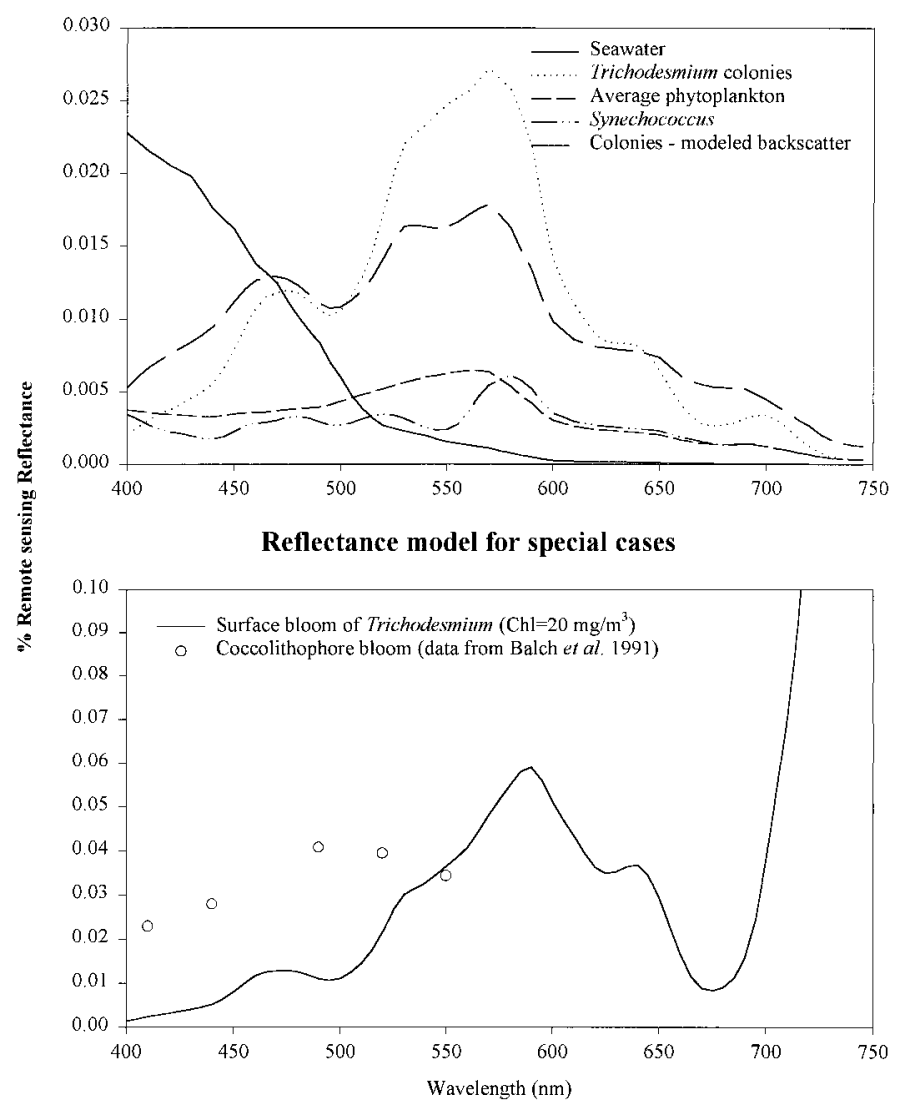

Fig. 5. (A) Reflectance model for chlorophyll $=10 \mathrm{mg} \mathrm{m}^{-3}$. (B) Reflectance model for special cases. It is obvious that the reflectance spectra of coccolithophores are completely different from Trichodesmium, and any ocean color sensor should be able to distinguish between the two. This is consistent with ship-board observations that have described coccolithophore blooms as blue or milky white, while Trichodesmium blooms have been described as golden yellow or red. Note the extremely high reflectance above $700 \mathrm{~nm}$ for Trichodesmium.

gilvin concentrations, the differences between the spectral characteristics of the retrieved reflectance are greatly attenuated, such that it would be difficult to unambiguously distinguish Trichodesmium from other phytoplankton (Fig. 4B).

At high chlorophyll concentrations $\left(\mathrm{Chl}=10 \mathrm{mg} \mathrm{m}^{-3}\right)$, Trichodesmium colonies could easily be distinguished from other phytoplankton and Synechococcus (Fig. 5A). The differences between trichomes and colonies were not considered in this case, as at such high chlorophyll concentrations virtually all cells would form colonies. Jones et al. (1982) pointed out that at such high concentrations, Trichodesmium exudes ultraviolet-absorbing substances, greatly increasing the absorption in the blue (Subramaniam et al. 1999). Therefore, the model was run only for high gilvin concentrations. The phycoerythrin absorption at $495 \mathrm{~nm}$ was clearly seen, as was fluorescence due to phycoerythrin at $570 \mathrm{~nm}$ and allophycocyanin at $640 \mathrm{~nm}$. Because we did not explicitly add a chlorophyll fluorescence component to the model, no chlorophyll fluorescence is noted for "other phytoplankton." However, this is a prominent feature in remote-sensing data containing blooms of eucaryotic phytoplankton.

The special case of surface blooms (Fig. 5B) was considered using a value of $5 \times 10^{5}$ colonies $\mathrm{m}^{-3}$ (corresponding to ca. 100 trichomes $\mathrm{ml}^{-1}$ or a chlorophyll concentration of approximately $20 \mathrm{mg} \mathrm{m}^{-3}$; Carpenter and Capone 1992). This concentration of chlorophyll is typical of surface scum blooms of Trichodesmium observed in tropical and subtropical gyres. Under such conditions, the organisms float at the air-sea interface, and their elastic backscatter and fluorescence cross-sections dominate the reflectance spectra, resulting in extremely high reflectance in the near-infrared portion of the spectrum. The modeled reflectances were much higher in this case ( $>7 \%$ compared to $<3 \%$ in earlier cases), comparable to reflectance from a dense coccolithophore bloom (data from Balch et al. 1991). However, Trichodesmium could be readily distinguished from coccolithophores by the spectral shape of the remote-sensing reflectance. Coccolithophore blooms had a high reflectance in the blue end of the spectrum but very low reflectance in the red (Fig. 5B), whereas the opposite is true for Trichodesmium.

An application of the optical model - Based on the results presented in Fig. 5B, we developed an "albedo vegetation index" (AVI) that could be used with the AVHRR, the only operational sensor in 1995 with visible and near-infrared sensors. The AVI was a dimensionless simple difference of the albedos of channel 1 and channel 2 of the AVHRR. Processed and navigated local area coverage AVHRR-normalized channel 1 and 2 albedo images were provided to us by Dr. Evans, RSMAS, University of Miami. This reflectionbased classifier identifies only vegetation on the surface of the water and hence, would not detect Trichodesmium that sinks in the water column later in the day.

Because there is no spectral information in this index, it cannot distinguish between Trichodesmium and other floating algae (e.g., Nodularia blooms in the Baltic Sea or Sargassum in the western North Atlantic) without in situ information. However, if sea truth existed to identify the bloom organism, the AVI could be used to map the extent of the bloom. Two such blooms were noted in the Arabian Sea in May 1995.

Scientists on board the RV Malcolm Baldridge noted a Trichodesmium bloom on 8 May at $10^{\circ} 2.51^{\prime} \mathrm{N}, 51^{\circ} 59.34^{\prime} \mathrm{E}$ off the Somali coast (Kramer pers. comm.). The sea state was described as "glassy calm" with streaks of Trichodesmium around the ship. A surface sample contained 16,900 trichomes $\mathrm{ml}^{-1}\left(4.25 \mathrm{mg} \mathrm{Chl} a \mathrm{~m}^{-3}\right)$. It was noted that the ship's flow-through fluorometer, pumping water from approximately $3 \mathrm{~m}$ below the surface, detected almost no chlorophyll. A large surface bloom was noted in this region more than 1 month later by scientists on a NASA P3 aircraft (McClean pers. comm.). Trichodesmium blooms were also reported in the Red Sea in the same time period (Dubinsky pers. comm.). AVHRR images from 20 and 25 May 1995, obtained from Dr. Evans, RSMAS, University of Miami, showed a large Trichodesmium bloom off the Somali coast and in the Red Sea (Fig. 6A,C). Another Trichodesmium 


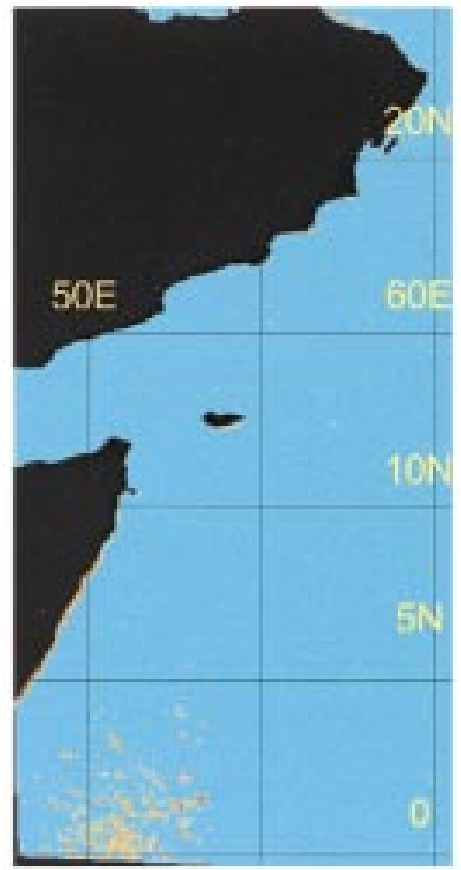

(A)

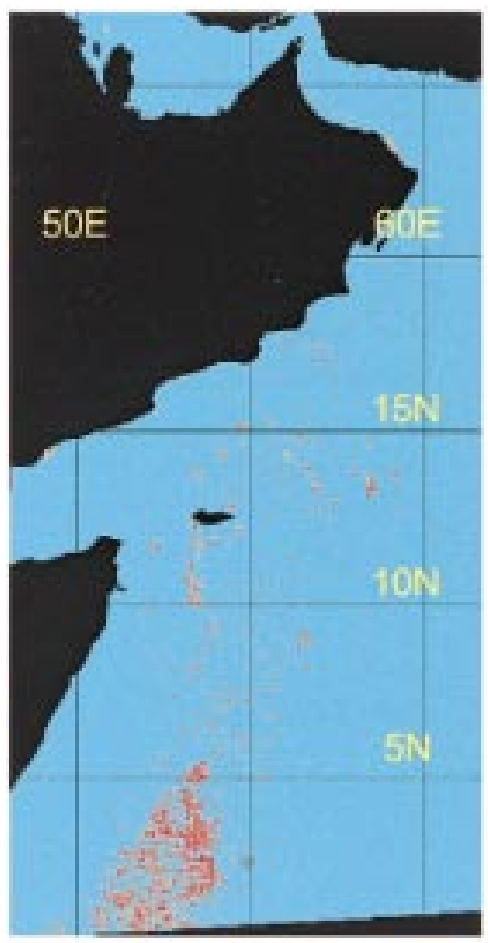

(C)

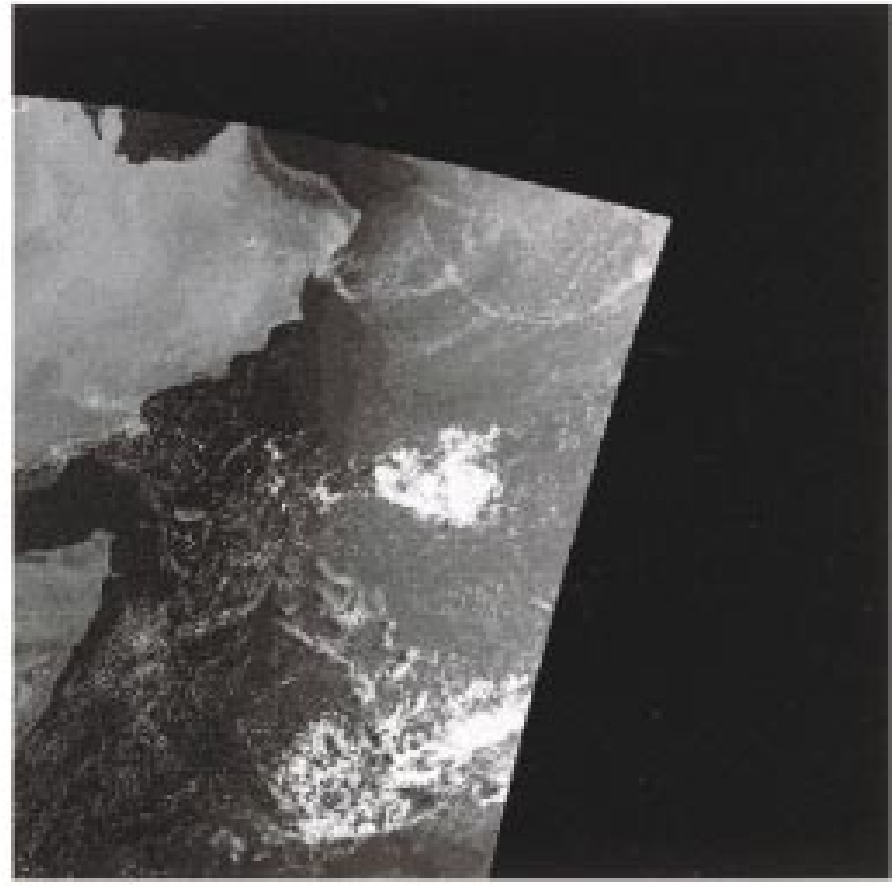

(B)

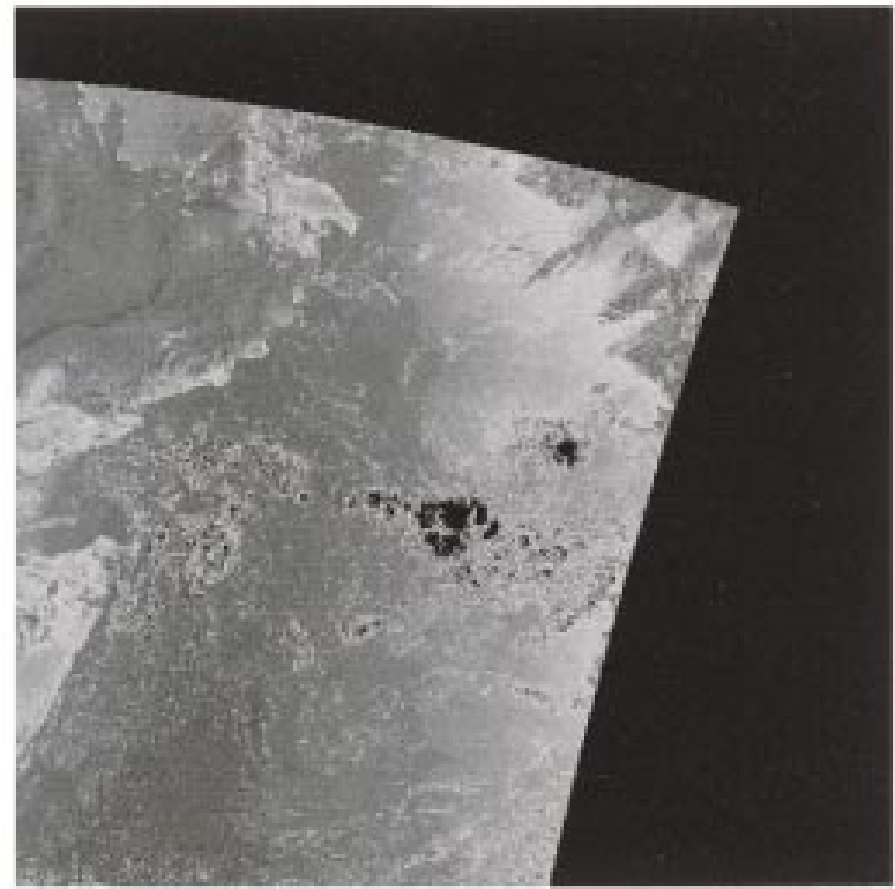

(D)

Fig. 6. Surface distributions of Trichodesmium in the Arabian Sea between 20 and 25 May 1995, based on a vegetation index derived from the albedo channels of NOAA 12 AVHRR images. Processed and navigated AVHRR-normalized channel 1 and 2 albedo images were provided to us by Dr. Evans, RSMAS, University of Miami. The processing was done using the DSP image processing software (University of Miami) at RSMAS, where local area coverage AVHRR images of the Arabian Sea were archived to support the USJOGFS program. The albedo values were scaled from 0 to 255. The MIA2TIFF procedure of DSP was used to create TIFF files of the images, and the TIFF_READ procedure of IDL (RSI) was used for further analysis of the images. A classifier similar to the Gray-McCrary Index (GMI) 
bloom in the central Arabian Sea was mapped using satellite imagery from 23 and 27 May 1995 (Capone et al. 1998).

\section{Discussion}

The results presented here are the first reported measurements of spectral backscattering coefficients from any gas vacuolate phytoplankton. They reveal an extremely high optical backscatter cross-section for Trichodesmium, which, in conjunction with its unique absorption and fluorescence characteristics, provides the basis for identifying and potentially quantifying these organisms in the global ocean from either remotely sensed data or in situ optical measurements. We first consider the backscatter signature of Trichodesmium in comparison with results reported for other phytoplankton.

Ahn et al. (1992) reported one of the most comprehensive analyses of spectral backscattering properties of phytoplankton. Using virtually the same experimental design presented here, Ahn et al. (1992) measured the spectral backscatter cross-sections from nine species of cultured phytoplankton, including a clone of Synechococcus. The values ranged from $0.23 \times 10^{-4}$ to $9.93 \times 10^{-4} \mathrm{~m}^{2}(\mathrm{mg} \mathrm{Chl} a)^{-1}$ at $550 \mathrm{~nm}$, compared with $20.0 \times 10^{-4} \mathrm{~m}^{2}(\mathrm{mg} \mathrm{Chl} a)^{-1}$ for Trichodesmium.

Ahn et al. (1992) assumed the phytoplankton cells to be perfectly homogeneous and spherical and used Mie theory to derive the backscatter cross-section. Mie theory is not directly applicable to Trichodesmium. The structure of Trichodesmium violates basic assumptions required for the numerical solution of the equations, namely sphericity and homogeneous structure. Trichodesmium colonies are typically cylindrical, about $3,000 \mu \mathrm{m}$ in length and $500 \mu \mathrm{m}$ in diameter. Up to $80 \%$ of the internal volume of Trichodesmium is made up of gas vacuoles, giving it a very severe internal structure with very large changes in relative refractive index (1.00-gas vacuoles, 1.37-cytoplasm, and 1.33-surrounding medium). The effects of shape and size are especially important in calculations of backscatter, and thus, assumptions of sphericity and homogeneity are even more problematic (Kirk 1976).

Davies-Colley et al. (1986) and Weidemann and Bannister (1986) calculated a chlorophyll-specific total scatter $(b)$ for gas vacuolate cyanobacteria to be $0.12 \mathrm{~m}^{2}(\mathrm{mg} \mathrm{Chl})^{-1}$ using a photosynthetically available radiation sensor. Jupp et al. (1994) used a backscattering efficiency of $1.9 \%$ to estimate a backscatter coefficient $\left(b_{b}\right)$ of about $0.0024 \mathrm{~m}^{2}(\mathrm{mg} \mathrm{Chl})^{-1}$ and found a good fit between their reflectance model based on this estimate and actual reflectance measurements of a freshwater cyanobacterial bloom. Our measurements are in excellent agreement with these numbers, i.e., an average chlorophyll-specific backscatter of $0.0023 \mathrm{~m}^{2}(\mathrm{mg} \mathrm{Chl})^{-1}$. The backscattering cross-sections and coefficients reported here for Trichodesmium are derived from separate measurements of the backscattering spectrum and the chlorophyllspecific volume-scattering function. We therefore suggest that the backscattering cross-sections reported here are robust.

The results of the remote-sensing reflectance model study reveal that it is possible to uniquely identify Trichodesmium from remotely sensed measurements in the visible portion of the spectrum, depending on the concentration of the organism in the water column. Quantification at concentrations below ca. $1 \mathrm{mg} \mathrm{Chl} a \mathrm{~m}^{-3}$ is problematic based on reflectance signatures alone. Subramaniam (1995) showed that Trichodesmium concentrations of $0.1 \mathrm{mg}$ chlorophyll $\mathrm{m}^{-3}$ were biogeochemically significant in the Caribbean Sea. Tassan (1995) did a sensitivity analysis on the potential for remote sensing of Trichodesmium using SeaWiFS and concluded that it should be possible to distinguish this organism at concentrations as low as $0.1-0.3 \mathrm{mg}$ chlorophyll $\mathrm{m}^{-3}$. At moderate Trichodesmium concentrations $(\mathrm{Chl}=1.0 \mathrm{mg}$ $\mathrm{m}^{-3}$ ), the increase in reflectance around $550 \mathrm{~nm}$, due to phycoerythrin fluorescence, can be used to distinguish Trichodesmium from other phytoplankton. If Trichodesmium were present at higher concentrations $\left(\mathrm{Chl}=10 \mathrm{mg} \mathrm{m}^{-3}\right)$, it would be very easy to distinguish it from all other phytoplankton, including Synechococcus and coccolithophores, using remotely sensible optical properties.

Although remote sensing of phytoplankton in the ocean is primarily based on water-leaving radiance in the visible, the colonial and buoyancy behaviors of gas vacuolate cyanobacteria offer opportunities to exploit the red and near-infrared regions of the spectrum as well. In the specific case of Trichodesmium, the virtual absence of solar-induced fluorescence of $\mathrm{Chl} a$, the optical brightness resulting from gas vacuoles, and the removal of absorption by water in the nearinfrared permitted the development of simple two-channel reflectance difference indices from AVHRR data to map distributions of surface blooms. While this approach is inferior to that utilizing visible color information, AVHRR data can be used to map, retrospectively, the distribution of surface blooms where there is simultaneous in situ information identifying the bloom organism. Such an approach is especially

$\leftarrow$

was developed for detection of surface blooms of Trichodesmium, based on a simple difference between albedos of channel 1 and 2 (Gray and McCrary 1981). The classifier for identification of Trichodesmium on the water surface consisted of the following steps: (1) All albedos $>200$ gray scale values were set to 0 . This removed clouds and other very highly reflective surfaces from further processing. (2) Determined $\mathrm{AVI}=\mathrm{alb} 2-$ alb1, where alb1 and alb2 were channel 1 and channel 2 albedos. (3) All pixels with values of AVI less than -5 or greater than 50 were set to 255. (4) All pixels with values equal to 0 were set to 255 (this now includes pixels whose channel 1 or 2 albedos were $>200$, whose AVI value was 0 , less than -5 , or greater than 50). This reflection-based classifier only identifies vegetation on the surface of the water. This classifier will not detect any phytoplankton in the water column, including Trichodesmium that sinks in the water column later in the day or coccolithophore blooms. (A) AVI response for 20 May 1995. The yellow and red speckles represent the Trichodesmium bloom. (B) Channel 1 albedo of AVHRR on NOAA 12 on 20 May 1995. (C) AVI response for 25 May 1995. (D) Channel 1 albedo of AVHRR on NOAA 12 on 25 May 1995. 
attractive during the critical years from 1986 to 1996, when AVHRR data, but no ocean color imagery, were available.

While the structure of our model is similar to that proposed by Borstad et al. (1992), the results and inferences differ. Borstad et al. concluded that it would be very difficult to identify, let alone quantify, Trichodesmium from remotesensing reflectance data, unless there were massive blooms or one had access to hyperspectral data. Our results are far more encouraging. Borstad et al. ignored phycoerythrin fluorescence from Trichodesmium, assuming that it would be overwhelmed by the green reflectance peak. Instead, they introduced a theoretical $\mathrm{Chl} a$ fluorescence efficiency term. Trichodesmium has no appreciable chlorophyll fluorescence in vivo (Subramaniam et al. 1999). The backscattering spectrum measurements presented here, however, include fluorescence due to phycoerythrin, which greatly enhances the reflectance in the green.

In practice, only gas vacuolate phytoplankton are capable of forming true surface blooms, where the absorption of light due to water can be ignored. Trichodesmium bloom concentrations as high as 38,600 trichomes $\mathrm{ml}^{-1}$ (corresponding to Chl $a$ concentrations of 7,720 mg Chl $a \mathrm{~m}^{-3}$ ) in the top 5 $\mathrm{cm}$ of the water column have been reported (Devassy et al. 1978). A more typical value of 100 trichomes $\mathrm{ml}^{-1}$ (chlorophyll concentration $=20 \mathrm{mg} \mathrm{Chl} a \mathrm{~m}^{-3}$; Carpenter and Capone 1992) was used in the model for a special case of surface scum blooms (Fig. 5B). The removal of the strong absorption due to water in the red (Fig. 2A) and the lack of noticeable pigment absorption at wavelengths of $>700 \mathrm{~nm}$ cause the reflectance due to a surface bloom of Trichodesmium to increase (Fig. 5B). Jupp et al. (1994) discussed the results of their model and field measurements, using airborne instruments, of a cyanobacterial bloom in a turbid freshwater lake in Australia. Figures 3 and 8 in their paper show very high reflectance between 700 and $850 \mathrm{~nm}$. Satellite algorithms for processing of Coastal Zone Color Scanner (CZCS), AVHRR, and SeaWiFS data use the water-leaving radiance in the near infrared $(750 \mathrm{~nm})$ to detect and flag clouds (Darzi 1992). The assumption was that the waterleaving radiance at these wavelengths would be small, and only clouds could contribute to any radiance detected by the sensor. However, our reflectance model results show that surface blooms of gas vacuolate phytoplankton could also contribute to reflectance at these wavelengths. Surface blooms of Trichodesmium could be misidentified as clouds in SeaWiFS and AVHRR imagery. However, the difference in reflectance in a band just below $700 \mathrm{~nm}$ and just above 700 nm (bands 5, 6 for SeaWiFS and bands 1, 2 for AVHRR) could be used to set "flags" to identify surface blooms of Trichodesmium.

We can extend the point measurements of Trichodesmium nitrogen fixation rates to estimate basin scale fluxes using the AVI. A bloom encountered by the RV Malcolm Baldrige had an average concentration of ca. 16,900 trichomes $\mathrm{ml}^{-1}$ (4.25 mg Chl $\left.a \mathrm{~m}^{-3}\right)$. Capone et al. (1998) measured the mean nitrogen fixed per trichome to be 1.143 pmol trichome $\mathrm{e}^{-1} \mathrm{~h}^{-1}$ and the mean nitrogen fixation rate to be 150 $\pm 10 \mu \mathrm{mol} \mathrm{N} \mathrm{m} \mathrm{N}^{-2} \mathrm{~d}^{-1}$ for another bloom in the eastern Arabian Sea at about the same time. The total spatial extent of the bloom mapped by the AVI on 25 May was $5.88 \times$
$10^{11} \mathrm{~m}^{2}$ (Fig. 6A). Thus, the nitrogen fixed by just this bloom was $9.348 \times 10^{8} \mathrm{gN} \mathrm{d}^{-1}$. The total nitrogen fixed by two blooms accounted for one-fifth the estimated annual nitrogen input of 4.5 Tg N for the Arabian Sea (Capone et al. 1998).

The results of the calculation presented here simply demonstrate the potential application of an algorithm that uniquely identifies and quantifies Trichodesmium on a basin scale. The uncertainty in nitrogen fixation in the oceans is approximately a factor of five, from ca. 20 to $90 \mathrm{Tg}$ per annum. This large uncertainty is almost entirely due to the lack of quantitative information about the spatial and temporal distribution of Trichodesmium. Ocean color sensors such as OCTS, MOS, SeaWiFS, and MODIS have requisite bands to detect Trichodesmium based on the remote-sensing reflectance models presented here, and hence, they should provide the capability to elucidate the role of this key organism in global biogeochemical cycles.

\section{References}

Ahn, Y. H., A. Bricaud, AND A. Morel. 1992. Light backscattering efficiency and related properties of some phytoplankters. Deep-Sea Res. 39: 1835-1855.

ANTOINE, D., J-M. ANDRE, AND A. Morel. 1996. Oceanic primary production. 2. Estimation at global scale from satellite (coastal zone color scanner) chlorophyll. Global Biogeochem. Cycles 10: $57-69$.

Austin, R. W. 1974. The remote sensing of spectral radiance from below the ocean surface, p. 317-344. In N. G. Jerlov and E. Steemann Nielsen [eds.], Optical aspects of oceanography. Academic.

Balch, W. M., P. M. Holligan, S. G. AcKleson, And K. J. Voss. 1991. Biological and optical properties of mesoscale coccolithophore blooms in the Gulf of Maine. Limnol. Oceanogr. 36: 629-643.

Behrenfeld, M. J., And P. G. Falkowski. 1997. Photosynthetic rates derived from satellite-based chlorophyll concentration. Limnol. Oceanogr. 42: 1-20.

Borstad, G. A., J. F. R. Gower, and E. J. Carpenter. 1992. Development of algorithms for remote sensing of Trichodesmium blooms, p. 193-210. In E. J. Carpenter, D. G. Capone, and J. G. Rueter [eds.], Marine pelagic cyanobacteria: Trichodesmium and other diazotrophs. Kluwer.

Capone, D. G., A. Subramaniam, J. P. Montoya, C. Humborg, M. Voss, F. Pollehne, And E. J. CARPenter. 1998. An extensive bloom of the diazotrophic cyanobacterium, Trichodesmium, in the Central Arabian Sea during the spring intermonsoon. Mar. Ecol. Prog. Ser. 172: 281-292.

- J. J. Zehr, H. W. PAerl, B. Bergman, and E. J. CARPenTER. 1997. Trichodesmium, a globally significant marine cyanobacterium. Science 276: 1221-1229.

Carder, K. L., S. K. Hawes, K. A. Baker, R. C. Smith, R. G. StewARD, AND B. G. Mitchell. 1991. Reflectance model for quantifying chlorophyll $a$ in the presence of productivity degradation products. J. Geophys. Res. 96: 599-611.

- AND R. G. STEWARD. 1985. A remote-sensing reflectance model of a red-tide dinoflagellate off West Florida. Limnol. Oceanogr. 30: 286-298.

- $\longrightarrow$, G. R. Harvey, And P. B. Ortner. 1989. Marine humic and fulvic acids: Their effects on remote sensing of ocean chlorophyll. Limnol. Oceanogr. 34: 68-81.

Carpenter, E. J., AND D. G. CAPONE. 1992. Nitrogen fixation in Trichodesmium blooms, p. 211-217. In E. J. Carpenter, D. G. 
Capone, and J. G. Rueter [eds.], Marine pelagic cyanobacteria: Trichodesmium and other diazotrophs. Kluwer.

DARZI, M. 1992. Cloud screening for polar orbiting visible and IR satellite sensors. NASA Technical Memo. 104566, v. 7, NASA Goddard Space Flight Center.

Davies-Colley, R. J., R. D. Pridmore, and J. E. Hewitt. 1986. Optical properties of some freshwater phytoplanktonic algae. Hydrobiologia 133: 165-178.

Devassy, V. P., P. M. A. Bhattathiri, And S. Z. QAsim. 1978. Trichodesmium phenomenon. Indian J. Mar. Sci. 7: 168-186.

FALKOWSKI, P. G. 1997. Evolution of the nitrogen cycle and its influence on the biological sequestration of $\mathrm{CO}_{2}$ in the ocean. Nature 387: 272-275.

GoRDON, H. R. 1976. Radiative transfer in the ocean: A method for determination of absorption and scattering properties. Appl. Opt. 40: 417-427.

- O. B. BRown, AND M. M. JACOBS. 1975. Computed relationships between the inherent and apparent optical properties of a flat homogenous ocean. Appl. Opt. 14: 417-427.

, AND A. Y. MoREL. 1983. Remote assessment of ocean color for interpretation of satellite visible imagery. A review. Springer.

GRAY, T. I., AND D. G. MCCRARY. 1981. Meteorological satellite data - a tool to describe the health of the world's agriculture. NOAA Technical Memo EW-N1-04042, JSC-17112.

Jones, G. B., C. Burdon-Jones, And F. G. Thomas. 1982. Influence of Trichodesmium red tides on trace metal cycling at a coastal station in the Great Barrier Reef Lagoon. Oceanol. Acta 5: 319-326.

Jupp, D. L. B., J. T. O. KirK, AND G. P. Harris. 1994. Detection, identification and mapping of cyanobacteria-using remote sensing to measure the optical quality of turbid inland waters. Aust. J. Mar. Freshwater Res. 45: 801-828.

KIRK, J. T. O. 1976. A theoretical analysis of the contributions of algal cells to the attenuation of light within natural waters. III. Cylindrical and spheroidal cells. New Phytol. 77: 341-358.

. 1984. Dependence of relationship between inherent and apparent optical properties of water on solar altitude. Limnol. Oceanogr. 29: 350-356.
1994. Light and photosynthesis in aquatic ecosystems. Cambridge Univ. Press.

Longhurst, A., S. Sathyendranath, T. Platt, and C. CaverHILL. 1995. An estimate of global primary production in the ocean from satellite radiometer data. J. Plankton Res. 17: $1245-1271$.

Morel, A. 1988. Optical modeling of the upper ocean in relation to its biogenous matter content (case 1 water). J. Geophys. Res. 93: 10749-10768.

, AND B. GENTILI. 1993. Diffuse reflectance of oceanic waters. 2. Bidirectional aspects. Appl. Opt. 32: 6864-6872.

, AND L. PRIEUR. 1977. Analysis of variations in ocean color. Limnol. Oceanogr. 22: 709-722.

Sathyendranath, S., L. Lazzara, and L. Prieur. 1987. Variations in the spectral values of specific absorption of phytoplankton. Limnol. Oceanogr. 32: 403-415.

Smith, R. C., AND K. S. BAKer. 1981. Optical properties of the clearest natural waters (200-800 nm). Appl. Opt. 20: $177-184$.

Strickland, J. D., AND T. R. PARsons. 1972. A practical handbook of seawater analysis. Bulletin of the Fisheries Research Board of Canada.

Subramaniam, A. 1995. Optical properties of the marine cyanobacteria Trichodesmium: Applications to remote sensing. Ph.D. thesis, SUNY at Stony Brook.

, and E. J. Carpenter. 1994. An empirically derived protocol for the detection of blooms of the marine cyanobacterium Trichodesmium using CZCS imagery. Int. J. Remote Sens. 15: 1559-1569. , - D. KARENTZ, AND P. G. FALKOWSKI. 1999. Optical properties of the marine diazotrophic cyanobacteria Trichodesmium spp. I. Absorption and spectral photosynthetic characteristics. Limnol. Oceanogr. 44: 608-617.

TASSAN, S. 1995. SeaWiFS potential for remote sensing of marine Trichodesmium at sub-bloom concentration. Int. J. Remote Sens. 16: 3619-3627.

Weidemann, A. D., AND T. T. BANNISTER. 1986. Absorption and scattering coefficients in Irondequoit Bay. Limnol. Oceanogr. 31: $567-583$.

Received: 26 November 1997 Accepted: 30 September 1998 Amended: 18 December 1998 